environment. The study supports the usage of multiple intervention strategies within a holistic approach that acknowledge these factors to prevent any future home injuries.

\section{BRAIN INJURIES AND FRACTURES FROM FALLS ON STAIRS AMONG CHILDREN AND YOUTH IN CANADA: EPIDEMIOLOGY AND PREVENTION}

1,2 Karlyn Olsen, ${ }^{2,3}$ Peter Barss, ${ }^{4}$ Lorena Hiscoe. ${ }^{1}$ University of Toronto; ${ }^{2}$ Canadian Red Cross Water Safety; ${ }^{3}$ Division of Occupational and Environmental Health, School of Population and Public Health, University of British Columbia, Vancouver, Canada; ${ }^{4}$ Lakehead University, Ontario, Canada

\subsection{6/injuryprev-2016-042156.210}

Background Stairs and steps have in some countries become the leading source of brain injury, with children and working age adults as the main populations at risk. Risk factors and trends were assessed for hospitalizations of children and youth $\leq 19$ years in Canada.

Methods Non-nominal hospital admission data were obtained from the Canadian Institute of Health Information for the years 1994-2009. Hospitalisations of children and youth 0-19 years of age due to falls on stairs and steps were extracted using appropriate ICD 9 and 10 codes. Trends by age group were analysed and hospitalizations cross classified using external cause and nature of injury codes. Statistical evaluation included $\chi^{2}$ for univariate and bivariate analysis and Poisson or negative binomial regression for trend analysis of hospitalizations and injuries.

Results There were 13,500 hospitalisations from falls on stairs and steps among 0-19 year olds. Rate of hospitalisation decreased by $55 \%$ over the study period from $16.8 / 100,000$ to $7.5 / 100,000$. Infants less than $<1$ year old had the highest rate at $33.2 / 100,000$, and the greatest improvement correlating in time with banning of baby walkers. Males represented $55 \%$ of patients. The home was the site of $60 \%$ of incidents, with $60 \%$ of falls resulting in a fracture and $30 \%$ in intracranial injury. For infants $<1$ year, 50\% of stair falls resulted in an intracranial injury. Income quintiles were highly correlated ( $\mathrm{p}<0.001)$, especially for lowest, at $25 \%$ of total, versus highest $16 \%$.

Conclusions Home stairs present serious hazards, especially for infants and children. While rates of stair falls have declined in the last two decades, much work remains to make stairs safer and prevent injuries, especially of the brain. Home stairs can be made less steep by adopting the 7-11 configuration widely adopted for public places, and other building code measures to correct frequent design and constuction hazards.

\section{PATIENT SAFETY THROUGH DOCUMENTATION: BARRIERS IDENTIFIED BY HEALTHCARE PROFESSIONALS AND STUDENTS}

${ }^{1}$ Victor Valderaune, ${ }^{1}$ Jorunn Bjerkan, ${ }^{2}$ Rose Mari Olsen. ${ }^{1}$ Faculty of Health and Science, Nord-Trondelag University College, Norway; ${ }^{2}$ Centre for Care Research Mid-Norway, Norway

\subsection{6/injuryprev-2016-042156.211}

Background Effective communication and accurate documentation is critical to delivering quality outcomes and patient safety in municipal elderly care. Yet it is becoming increasingly apparent that healthcare providers struggle to coordinate health information exchange, and are more likely to have inaccurate and incomplete clinical information. The aim of the study was to explore healthcare professionals' and students' perceptions of barriers to patient safety and quality in their documentation practice. This knowledge could facilitate the development and implementation of improved documentation practice and information exchange among healthcare professionals.

Methods A qualitative exploratory design with six focus group interviews were used. The study included a purposive sample of nurses and social educators $(n=12)$ from primary care, and nurse- and social educator students (at Bachelor's level) ( $n=11)$. The data were analysed by content analysis.

Results Four main themes about barriers to patient safety emerged from the analysis: "Individual factors", "Social factors", "Organisational factors", and "Technological factors". Each theme included several sub-themes. A conceptual model was developed to illustrate the relationships between the themes.

Conclusions According to the findings, several barriers negatively influence documentation and information exchange and may put the patients in primary care in a vulnerable and exposed situation. To achieve successful documentation, more awareness and effort from the individual professional is required. However, it is critical that primary care services facilitate this through adequate resources, clear missions, and understandable policies.

\section{OIL SPILLAGE EFFECTS ON HEALTH AND SAFETY AMONG THE LOCAL COMMUNITIES - EXPERIENCE FROM BANGLADESH}

${ }^{1}$ Shafkat Hossain, ${ }^{1}$ Abu Sayeed Abdullah, 'Jahangir Hossain, ${ }^{1}$ Aminur Rahman, ${ }^{1,2}$ Animesh Biswas. ${ }^{1}$ Centre for Injury Prevention and Research, Bangladesh (CIPRB), Bangladesh; ${ }^{2}$ Örebro University, Sweden

\subsection{6/injuryprev-2016-042156.212}

Background on $9^{\text {th }}$ December 2014 an oil tanker collided with a cargo vessel at Sundarban, the largest mangrove forest in the world. About 350, 000 litres of furnace oil spilled into the Shela river. No major oil clean-up was in placed due to lack of equipments and experiences. However, most of the local people including children came to the place without any safety measures to collect oil so that they could sell it later.

Methods Qualitative method was used to explore the situation. IDI, FGD, observation technique and relevant daily national and international newspapers were reviewed to collect the information.

Results The disaster affected both on health and safety of the community. Primarily local people, who do not have any previous experience, were involved to collect the oil from the river and government showed interest to procure the furnace oil at a fix rate. This lead local community to start collecting oil and later on faced various health problems like diarrhoea, skin diseases, abdominal pain and headache etc. A child drowning case was found due to collecting oil. Though 7-year old kid was rescued he suffered from diarrhoea for four days. To get the better quality of oil community people boiled the oil so that water evaporated and quality of it became better. Females were involved in boiling oil and they faced severe headache, irritation on eyes and nose and vomiting tendency.

Conclusion Disaster preparedness is essential for any country like Bangladesh. Government should take necessary initiative on awareness and safety before involving local community in any disaster management especially dealing with chemicals2. 